\section{THU0475 INCIDENCE AND DETERMINANTS OF VERTEBRAL AND PERIPHERAL FRACTURES IN PATIENTS WITH SYSTEMIC LUPUS ERYTHEMATOSUS: A PROSPECTIVE LONGITUDINAL COHORT STUDY}

F. El Hadiyen ${ }^{1}$, M. Tsang-A-Sjoe ${ }^{1}$, M. ter Wee ${ }^{1,2}$, A. Voskuyl ${ }^{1}$, W. Lems ${ }^{1}$, I. Bultink'. ${ }^{1}$ Department of Rheumatology; ${ }^{2}$ Department of Epidemiology and Biostatistics, VU University Medical Center, Amsterdam, Netherlands

Background: Systemic lupus erythematosus (SLE) is associated with an increased risk of fractures ${ }^{1}$. However, data on the incidence of vertebral and peripheral fractures are limited. In particular, data on (morphometric) vertebral fracture incidence and determinants of such fractures are scarce and show conflicting results.

Objectives: To assess the incidence of fractures in a population of patients with SLE, and to identify determinants that predict incident vertebral and peripheral fractures.

Methods: A prospective longitudinal cohort study in 145 patients with SLE was performed. Serial bone mineral density (BMD) measurements using dual x-ray absorptiometry, and radiographs of the thoracic and lumbar spine were performed at inclusion and after a median of 5 years (IQR 3-5) follow-up. Demographic and clinical data were also collected. Vertebral fractures were scored according to the semi-quantitative method by Genant et al. Reported peripheral fractures were confirmed by $x$-rays. Analyses were performed with logistic regression (forward selection procedure, $\mathrm{p}$-value of 0.05 as cut-off level). The outcome measures were incident fracture in general (yes/no), vertebral fracture (yes/no), and peripheral fracture (yes/no)

Results: Of the 145 included patients, $131(90 \%)$ were females and $100(69 \%)$ Caucasian. The mean age was 41 years (SD 12) at baseline, and median followup was 7.2 years (IQR 6-12). A total of 42 incident fractures (vertebral and peripheral) occurred during 998 patient years. The incidence rate of vertebral and peripheral fractures was 2.0 per 100 patient years $(95 \% \mathrm{Cl} 1.30-3.13)$, and 2.20 per 100 patient years $(95 \% \mathrm{Cl} 1.45-3.35)$, respectively.

Any fracture (both vertebral and peripheral) was predicted by postmenopausal status and Caucasian ethnicity. Vertebral fractures were predicted by age, in which the older the SLE patient, the higher the odds of getting vertebral fractures. Peripheral fractures were predicted by history of stroke, postmenopausal status and moderate alcohol use (1-12 units per week). Use of higher dosages of alcohol ( $>13$ units per week) did not reduce peripheral fracture occurrence. Table 1 shows the final prediction models.

Conclusions: The results of our study suggest a twofold increased risk of both vertebral and peripheral fractures in SLE patients compared to the general population $^{1,2}$. Age, Caucasian ethnicity and postmenopausal status are important risk factors for incident fractures in SLE. In addition, special attention should be paid to SLE patients with a history of stroke since this subgroup of patients is at high risk of peripheral fractures.

\section{REFERENCES:}

[1] Bultink IEM, et al. Osteoporos Int 2014;25:1275-83

[2] Ballane G, et al. Osteoporos Int 2017;28:1531-42.

Disclosure of Interest: F. El Hadiyen: None declared, M. Tsang-A-Sjoe: None declared, M. ter Wee: None declared, A. Voskuyl: None declared, W. Lems: None declared, I. Bultink Speakers bureau: Lilly Netherlands, MSD, Amgen BV, UCB Pharma BV, Sanofi Genzyme BV

DOI: 10.1136/annrheumdis-2018-eular.5938

\section{THU0476 \\ SPONTANEOUS VERTEBRAL FRACTURESAFTER DENOSUMAB DISCONTINUATION: A REPORT OF 6 CASES}

H. Florez, J. Ramírez, A. Monegal, N. Guañabens, P. Peris. Department of Rheumatology, Hospital Clínic, Barcelona, Spain

Background: Denosumab (Dmab) is an antiresorptive treatment with demonstrated efficacy in osteoporosis. However, discontinuation of Dmab has been associated with rapid bone loss, and recently, the development of vertebral fractures (VF) in some patients. It is essential to identify the risk factors for these adverse events and follow its evolution.

Objectives: To analyse the clinical characteristics, parameters of bone metabolism and evolution of patients developing VF after Dmab discontinuation.

Methods: Six women with spontaneous VF after Dmab discontinuation were included (median age 66 years ${ }^{56-75}$ ). The clinical history, cause of osteoporosis, treatments received, fractures, Dmab treatment duration and discontinuation period were reviewed. Additionally, the clinical and densitometric evolution, and bone mineral parameters were also analysed after Dmab discontinuation.

Results: All the patients had postmenopausal osteoporosis, and one was receiving glucocorticoid treatment; $3 / 6$ patients had previous fractures ( $2 \mathrm{VF}$ and $1 \mathrm{cal}-$ caneus); $4 / 6$ had previously received antiosteoporotic treatment (hormone replacement therapy, risedronate, alendronate, zoledronate [once or consecutively)] during 1-23 years. All had received Dmab for 24-53 months (median 37). The reasons for treatment discontinuation were: dental indication (1 patient), BMD improvement (T-score -1.2) (1 patient), poor adherence, ${ }^{1}$ prescription problems and/or delay in administration. ${ }^{3}$ The median bone mineral density T-scores prior to VF were $-2.6(-1.2 /-4)$ at the lumbar spine and $-3.0(-0.6 /-3.7)$ at the femoral neck. The mean time between the last Dmab dose and VF was 9.5 months, ${ }^{8-20}$ with a median of $5 \mathrm{VFs} /$ patient. $^{2-8}$ No patient showed $25-\mathrm{OH}$ vitamin $\mathrm{D}<20 \mathrm{ng} / \mathrm{ml}$. After Dmab discontinuation, bone turnover markers increased (median increase $+364 \%$ in PINP and $+287 \%$ in NTx); one patient presented hypercalcae$\mathrm{mia}$ (Ca $11.3 \mathrm{mg} / \mathrm{dL}$ ); and BMD decreased $1 \%-21 \%$ in the lumbar spine and $2 \%-$ $6 \%$ in total hip at 8-19 months. After VF, 3 patients restarted Dmab, 1 received zoledronate and 2 alendronate. No new fractures occurred during follow-up.

Conclusions: Discontinuation of Dmab is associated with an increase in bone turnover markers and bone loss which can be associated with the development of spontaneous VF. Previous bisphosphonate therapy does not seem to decrease this risk. Further studies are needed to assess the optimal antiresorptive treatment and its duration after Dmab discontinuation.

Disclosure of Interest: None declared

DOI: 10.1136/annrheumdis-2018-eular.4896

\section{THU0477 FACTORS ASSOCIATED WITH THE INITIATION OF TREATMENT AFTER FRAGILITY FRACTURE IN A FRACTURE LIAISON SERVICE}

A. Saavedra ${ }^{1}$, A. Naranjo ${ }^{1}$, S. Ojeda ${ }^{1}$, R. Lopez ${ }^{1}$, A. Molina ${ }^{1}$, C. Alonso ${ }^{2}$, I. Bernardos ${ }^{1}$, C. Rodriguez-Lozano ${ }^{1} .{ }^{1}$ Rheumatology; ${ }^{2}$ Radiology, Hospital Univ. Gran Canaria Dr. Negrin, Las Palmas de Gran Canaria, Spain

Background: Adherence to treatment in osteoporosis (OP) is not adequate, so that in the first year the percentage of suspensions is between $30 \%$ and $50 \%$, up to an adherence of $20 \%$ at 3 years. In 2012, we started in Gran Canaria a Fracture Liaison Service (FLS).

Abstract THU0475 - Table 1. Multivariate logistic regression analyses of independent explanatory variables that predict incident fracture, showing OR and $95 \% \mathrm{Cl}$

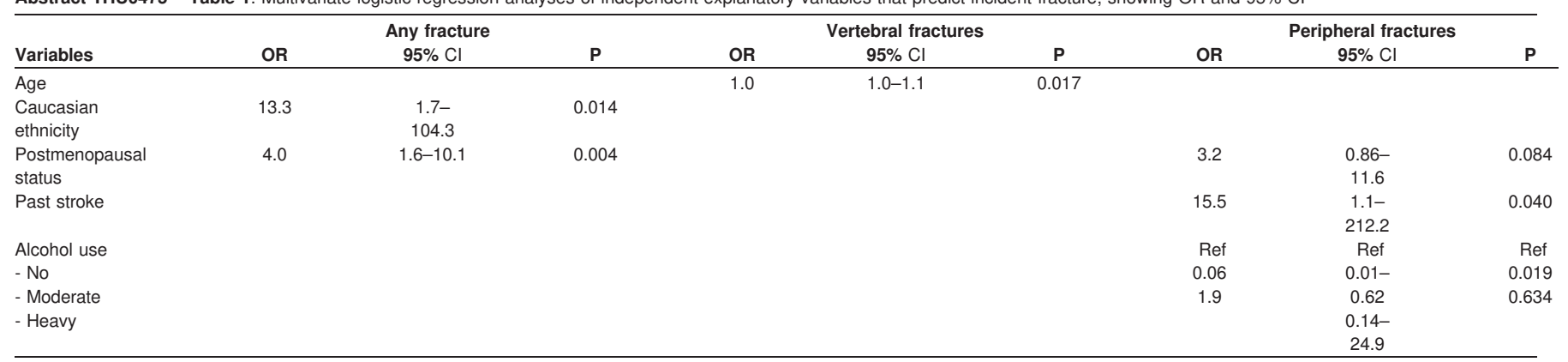

